\title{
Analysis on the Significance of Strengthening the International Communication of TCM culture
}

\author{
Xueli Ding ${ }^{1}$, Dejun $\mathrm{Li}^{2, *}$, Fangmeng $\mathrm{Li}^{3}$ \\ ${ }^{1}$ School of Foreign Languages, Hubei University of Chinese Medicine, Wuhan, P. R. China, 430065 \\ ${ }^{2}$ School of Foreign Languages, Hubei University of Chinese Medicine, Wuhan, P. R. China, 430065 \\ ${ }^{3}$ School of Foreign Languages, Hubei University of Chinese Medicine, Wuhan, P. R. China, 430065 \\ ${ }^{*}$ Corresponding author. Email: jasonldj@qq.com
}

\begin{abstract}
The culture of traditional Chinese medicine (TCM for short) embodies the essence of traditional Chinese culture and is an important carrier for Chinese civilization to be spread around the world. Promoting the international communication of TCM culture will effectively narrow the distance between the people of other countries and Chinese culture, and promote the widespread communication of Chinese culture in different countries and regions, which is of great significance to expand the international influence of China's cultural soft power, promote the spiritual connection and harmony between Chinese and people of other countries, and enhance the role of TCM played in safeguarding human health and well-being. Therefore, China should take active measures to further promote the communication of TCM culture to make TCM benefit more ordinary people.
\end{abstract}

Keywords: TCM culture, International Communication, the Significance.

\section{INTRODUCTION}

TCM is a unique cultural and medical treasure of China. It is not only an important cultural symbol of the Chinese nation, but also occupies an important place in the world cultural treasure house, and it has always been an important carrier for Chinese civilization to spread throughout the world. With the embodiment of the holistic view, the dialectical thought of harmony between yin and Yang, and the values of balance rather than confrontation, it can exert significant influences on the establishment of an inclusive and harmonious world. Meanwhile, as an important medical resource, TCM has been playing an important part in safeguarding human health and well-being since ancient times. Especially in the current process of fighting against the COVID-19 pandemic, the significant role played by TCM has once again drawn great public attention in the international community. On account of this, since the founding of People's Republic of China, the Chinese government has been attaching great importance to the international exchange and cooperation of TCM, and expecting TCM to play a greater part in the country's external cultural and medical exchanges.

The international exchange and cooperation of TCM, in essence, mainly refers to the international exchange and communication of TCM culture, that is, through the international communication of TCM culture, people around the world can better identify with the basic TCM theories and its methods of disease diagnosis and treatment, which could help people to continuously accept TCM culture and gradually apply the methods of TCM diagnosis and treatment to their daily health care activities, so as to make TCM truly go abroad and escort the lives and health of people all over the world. ${ }^{[1]}$ Therefore, in order to make TCM better promote China's external cultural exchanges and medical cooperation, it is of great necessity to first deeply explore the concept connotation and core values of TCM culture, and then comprehensively analyse the significance of the international communication of TCM culture in promoting China's external cultural and medical exchanges, so as to better arrange the communication of TCM culture in different countries and regions.

\section{THE CONCEPT CONNOTATION AND CORE VALUES OF TCM CULTURE}

\subsection{The Concept Connotation of TCM Culture}

In terms of the concept connotation of TCM culture, 
the domestic academic community of TCM so far has not yet reached a general consensus owing to its richness, and different scholars have put forward different views. For example, Mr. Ren Jiyu, a famous Chinese scholar, believes that TCM culture is the cultural essence of TCM formed in the process of accumulation and development of TCM over thousands of years. It is the embodiment of the profound philosophical ideas, lofty moral values and excellent cultural wisdom of the Chinese nation in the field of TCM, which dominates the basic characteristics and directions of TCM, and is the integration of TCM's internal values and mode of thinking with its external behavioural norms. ${ }^{[2]}$ A famous expert in TCM culture, Professor Zhang Qicheng, deems that "TCM culture is the combination of TCM's internal values and mode of thinking with its external behavioural norms and specific articles and images." ${ }^{[3]} \mathrm{He}$ vividly divides TCM culture into three dimensions: Heart, Hand and Face, in which Heart refers to the internal values and mode of thinking of TCM culture, Hand means the system, behaviour and management of TCM culture, and Face implies the environmental image and reputation of TCM culture. Professor Wen Changlu, an academic consultant of China Association of Chinese Medicine, advocates that TCM culture, in essence, constitutes the matrix of TCM, and is an integral part of the splendid Chinese culture; Functionally speaking, it is also an important carrier to inherit and spread TCM, contributing to its thousands of years of glorious and civilized development. He claims that the core of TCM culture refers to "the cultural concept dominated by benevolence, harmony, modesty and integrity, the cultural practice guided by precision, cautiousness, strictness and simplicity, and the cultural environment mainly with beauty, elegance, comfort and convenience" $"[4]$.

A reasonable interpretation of the concept connotation of TCM culture is the key to our scientific understanding, inheritance and spread of TCM culture. Therefore, when defining the concept connotation of TCM culture, we should give a comprehensive understanding to its essence and characteristics, adhere to the principles that are conducive to the establishment of TCM theoretical system, the inheritance, spread and innovation of TCM culture, the cultivation of TCM practitioners and the sustainable development of TCM. Based on the above principles, the concept connotation of TCM culture can be defined as the sum of spiritual civilization and material civilization that reflect the essence and characteristics of TCM in the excellent traditional Chinese culture, which is based on traditional Chinese philosophy, literature and history. It consists of TCM spiritual culture, behavioural culture and material culture, which includes three dimensions: TCM cultural concept, cultural practice and cultural environment. It embodies the humanistic attribute of TCM, which functions to shape the core ideology and values of TCM culture, form the thinking mode and cognition of TCM, reveal the laws of TCM, affect the inheritance and development of TCM, enhance the cultural identity and self-confidence of the Chinese nation, and expand the influence of Chinese culture.

\subsection{The Core Values of TCM Culture}

The core values of TCM culture, as its soul, dominate the existence and development of TCM culture. They are the cultural essence accumulated in the development of TCM for thousands of years and the concentrated embodiment of profound philosophical thought, noble moral sentiment and outstanding civilization of the Chinese nation in TCM. With the continuous in-depth study of the concept connotation of TCM culture by domestic scholars, more and more different refinements of the core values of TCM culture have emerged accordingly. Currently, the domestic TCM scholars generally recognized the defining of the core values of TCM culture in the Guidelines for the Construction of TCM Culture in TCM Hospitals. It points out that the core values of TCM culture are mainly embodied in the notions of benevolent medical heart, harmonious medical knowledge, excellent medical skills and sincere medical ethics, which could thereby be summarized in the four words of Ren (benevolence), He (harmoniousness), Jing (excellence) and Cheng (sincerity). The defining can well reflect the profound philosophical thoughts and brilliant civilization and wisdom of the Chinese nation in TCM, which regulates the integral unity of medical technology and medical ethics and is a concrete portrayal of the medical professionalism. ${ }^{[5]}$

Specifically, "Ren" in TCM culture reflects the ethical thought of loving others and life-first, which mainly involves in the two aspects of benevolence of doctors and benevolence in medical science. Benevolence of doctors reflects the benevolence thought of TCM practitioners who revere and cherish lives, as well as their faithful behaviours in the process of medical practice. Benevolence in medical science reveals the essential characteristics of medicine and the spirit of medical ethics for doctors to benefit mankind, heal the wounded and rescue the dying. "He" in TCM culture embodies the value orientation of TCM in advocating harmony, which is mainly manifested in the holistic view of harmony between man and nature, the health view of balance between yin and yang, the treatment view of complementarity between reconciliation and moderation, and the moral view of trust between doctors and patients, as well as humility among fellow practitioners. It is considered as the foundation of the endless circle of life in TCM, and also the soul and core value of TCM culture. "Jing" in TCM culture implies the assiduous and devoting academic 
attitude of TCM, which requires practitioners to concentrate on the refinement of their medical skills, cultivate the down-to-earth abilities in discernment and practice, and devote their whole lives to the training and refining of medical skills. When confronted with difficult miscellaneous diseases, it could save practitioners from bewilderment, and make them better heal the wounded and rescue the dying, rather than being impetuous, paranoid and sciolistic, and blindly following the hearsay. "Cheng" in TCM culture highlights the personality cultivation of TCM practitioners, which advocates sincerity in heart and honesty in words and deeds. It is the highest stage of practitioners' moral cultivation, which requires them to be sincere, honest and trustworthy in medical training and practice, medical works writing and compiling, and drug processing and prescription, instead of lying and being alarmist.

\section{THE SIGNIFICANCE OF PROMOTING THE INTERNATIONAL COMMUNICATION OF TCM CULTURE}

\subsection{Promoting the International Appeal of Chinese Culture and Enhancing the International Influence of China's Cultural Soft Power}

In the current era of political democratization and economic globalization, soft power has become an important indicator of a country's comprehensive national strength in today's international community. As a symbol of a country's national identity, culture has now become a core element of a country's soft power due to its strong power in cohesion, attraction and appeal, and is playing an increasingly important role in realizing domestic stability, unity and harmony and promoting international peace, cooperation and mutual benefits.

With its long history and extensive content, TCM culture not only has a unique medical theoretical system, but also includes some core values of Chinese culture, such as the life concept of "people-oriented", the holistic view of "the unity of heaven and humanity", the harmonious view of "dynamic balance", the ethical view of "great physicians with lofty virtues", etc. It is a treasure of traditional Chinese culture, reflects the cognitive mode and value orientation of the Chinese nation, and embodies the soft power of China. Zhang Boli, an academician of Chinese Academy of Engineering, once pointed out that TCM culture was an integral part of traditional Chinese culture and an outstanding representative of China's cultural soft power. Therefore, we should vigorously promote the construction and spread of TCM culture, so that people can better carry forward, inherit and propagate excellent Chinese culture while enjoying the medical services, and contribute to the construction of China's cultural soft power with their own efforts. The in-depth and comprehensive promotion of the international communication of TCM culture will help people in other countries view Chinese culture more objectively and reasonably, and evaluate Chinese culture more scientifically and rationally, which could better promote the international communication, integration and development of Chinese culture. In this process, the attraction and appeal of Chinese culture abroad will be further strengthened, and the international influence of China's cultural soft power will be greatly increased.

\subsection{Advancing the Building of Closer People- to-People Ties Between China and other Countries and furthering Political Mutual Trust and Economic Cooperation}

In today's international community, the closer people-to-people ties are an important public foundation for countries to carry out friendly exchanges and continuously enhance political mutual trust and economic cooperation, and the core of the closer peopleto-people ties is cultural exchange and cooperation. Mutual understanding, respect and trust on culture can break the estrangement caused by differences in race, language, religion, system and development model among different countries, make the people of all countries have a common ideological understanding and work together to exchange and cooperate with each other in political, economic and other fields.

TCM culture is one of the most important symbols of traditional Chinese culture. The rich cultural value and medical value contained in it is most likely to create a cultural brand of the Chinese nation, and promote Chinese culture to the world through the export of national cultural brand. Therefore, as an important element of traditional Chinese culture, the communication and exchange of TCM culture in other countries will fully display the great charm of Chinese culture, enhance the affinity and international influence of Chinese culture, so that more and more people from other countries can actively and objectively understand Chinese culture and consciously abandon the misunderstandings and prejudices on Chinese culture, which could help them gradually strengthen the spiritual connection with Chinese people on the basis of cultural identity, understanding and respect. The strong spiritual connection will undoubtedly help to eliminate the estrangement and obstacles between China and other countries, enhance mutual friendship and consensus, and lay a solid public foundation for the smooth development in various fields. It can be said that the international communication of TCM culture is an important starting point for the building of closer people-to-people ties, and one of the most significant 
means for China to further political mutual trust and economic cooperation with other countries.

\subsection{Improving the Health and Well-being of Mankind and Facilitating the Building of a Global Community of Health for All}

Health is a common topic faced by human society, a fundamental condition for the economic and social development of a country, and the primary symbol of a country's national prosperity. As an important ideological and methodological system for Chinese nation to understand life, maintain health and prevent diseases for thousands of years, it has always been the most important means for Chinese people to treat and prevent diseases, improve health and prolong life. Until now, confronted with some new serious threats to human health, such as AIDS, malignant tumours and infectious diseases, TCM therapy or the combined use of TCM and Western medicine can still achieve good therapeutic effects, especially in the fight against COVID-19 pandemic in 2020, TCM played an important role and became a highlight of the pandemic prevention and control.

In recent years, with the change of health concept and medical model, the efficacy and role of TCM played in the prevention and treatment of common diseases, frequently-occurring diseases, chronic diseases and major diseases have been continuously accepted and recognized by the international community, and more and more countries begin to strengthen cooperation with China in the field of TCM, which greatly accelerates the internationalization of TCM and creates a precious opportunity for TCM to go abroad and develop at a higher level in the world. Under this background, in order to make TCM better benefit the health and wellbeing of people all around the world in the future, in addition to continuing to strengthen cooperation with other countries in medical field, it is also necessary to further promote the international communication of TCM culture. Only by comprehensively and objectively understanding TCM culture can people from other countries have a scientific and rational interpretation of TCM, which could gradually cultivate their recognition of TCM theories and diagnosis and treatment methods, and finally make them willing to take the initiative to treat and prevent diseases with TCM. Therefore, it can be seen that the spread and popularization of TCM culture in other countries can better integrate TCM into the daily medical activities of foreign civilians, which is of great significance to improve the health and wellbeing of mankind and facilitate the building of a global community of health for all.

\section{CONCLUSION}

TCM culture is the foundation and soul of TCM, and is recognized as one of the most original and attractive contents of Chinese culture by academia at home and abroad. In order to better promote the participation of TCM in the construction and development of the country, when spreading TCM culture to the outside world, we must surpass the barriers of language and culture, break the restrictions of different industries, emancipate our mind and abandon outdated notions to regard the international communication of TCM culture as an overall project, incorporate it into the national strategy, and adhere to the principle of combining government leadership with non-governmental participation to gradually establish a mature multilateral cooperation mechanism for international communication through overall planning and active coordination. In the meantime, we should make efforts to build a three-dimensional and sustainable communication pattern of TCM culture by constantly innovating communication methods, broadening communication channels, and cultivating excellent international communication talents, so as to promote the comprehensive and in-depth communication of TCM culture in more countries, and make TCM benefit more ordinary people of other countries.

\section{RESEARCH PROJECT}

This paper is a research finding of the project "Study on the Cultivation of English Talents for the international communication of TCM culture under the Theory of Interculturality" (Project Number: 2020B13). The project is sponsored by the 2020 Monographic Project on the International Education Planning of TCM of Hubei University of Chinese Medicine.

\section{REFERENCES}

[1] Yao Yueming, Analysis on the internationalization of TCM hospitals through the Belt and Road Initiative, in: Jiangsu Health System Management, 2018(05), pp. 495-497, 529.

[2] $\mathrm{Yu}$ Xuefen, The concept, connotation and core content of TCM culture, in: Jiangxi Journal of Traditional Chinese Medicine, 2012(06), pp. 3-4.

[3] Zhang Zongming, The basic way to revitalize traditional Chinese medicine: the renaissance of TCM Culture, in: Journal Of Nanjing University of Chinese Medicine (Social Science Edition), 2011(01), pp. 1-8.

[4] Wen Changlu, The neutralization in traditional Chinese medicine and TCM culture, in: Global Traditional Chinese Medicine, 2010(01), pp. 58-61.

[5] Du Changhao. The core values of TCM culture-benevolence, harmony, precision and sincerity, in: China News of Traditional Chinese Medicine, 2013-2-27, Section 3. 